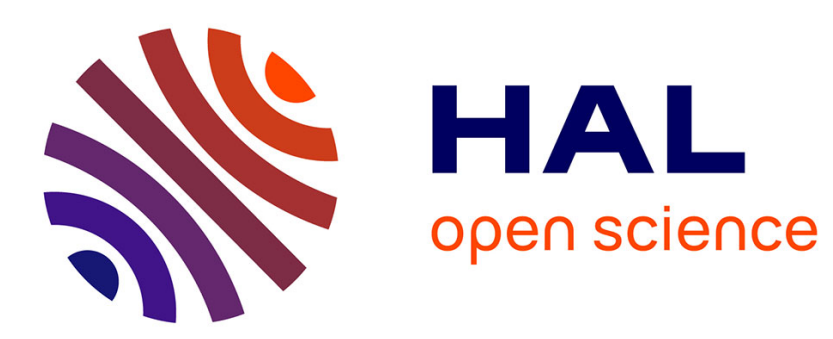

\title{
The use of questions in exhibit labels to generate explanatory conversation among science museum visitors
}

Justin Dillon

\section{To cite this version:}

Justin Dillon. The use of questions in exhibit labels to generate explanatory conversation among science museum visitors. International Journal of Science Education, 2007, 29 (12), pp.1557-1580. 10.1080/09500690701494068 . hal-00513351

\section{HAL Id: hal-00513351 \\ https://hal.science/hal-00513351}

Submitted on 1 Sep 2010

HAL is a multi-disciplinary open access archive for the deposit and dissemination of scientific research documents, whether they are published or not. The documents may come from teaching and research institutions in France or abroad, or from public or private research centers.
L'archive ouverte pluridisciplinaire HAL, est destinée au dépôt et à la diffusion de documents scientifiques de niveau recherche, publiés ou non, émanant des établissements d'enseignement et de recherche français ou étrangers, des laboratoires publics ou privés. 


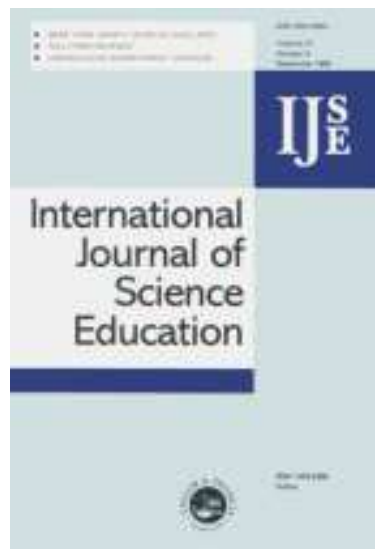

The use of questions in exhibit labels to generate explanatory conversation among science museum visitors

\begin{tabular}{|r|l|}
\hline Journal: & International Journal of Science Education \\
\hline Manuscript ID: & TSED-2007-0176 \\
\hline Manuscript Type: & Special Issue Research Paper \\
\hline Keywords: & informal education \\
\hline Keywords (user): & \\
\hline \multicolumn{2}{|l}{} \\
\hline
\end{tabular}

\section{S ScholaroNE \\ Manuscript Central}


The use of questions in exhibit labels to generate explanatory conversation among science museum visitors

Jill Hohenstein and Lynn Uyen Tran King's College London, United Kingdom 
The use of questions in exhibit labels to generate explanatory conversation among science museum visitors

Research suggests that conversations at museums contribute to as well as serve as evidence for learning. Many museums use labels to provide visitors with information as well as stimulate conversation about exhibit topics. However, most studies on exhibit labels do not centre on conversations. This investigation uses a Vygotskian framework to examine the ways questions in exhibit labels can stimulate conversations in a science museum. We examined the questions and explanations that appeared in conversation occurring under three label conditions (current label, added question: 'Why is this here?', and simplified text plus question) at three exhibits in a science museum. Each exhibit (a model of a Victorian workshop, a sectioned 1959 Austin Mini Cooper, and a bowl which survived the atomic bomb in Hiroshima, Japan) was videotaped for approximately six hours in each condition. Findings based on 464 conversations at these exhibits indicated that our guiding question affected visitors' conversations; however, adding the question had different effects at different exhibits. For example, at the Mini-Cooper exhibit, people asked more open-ended questions with the question added than in the current label condition. At this exhibit there were also more open-ended questions used in conjunction with explanatory responses when the question was present. In contrast, the guiding question at the Hiroshima bowl exhibit had no effect. These results imply that it is important to consider the nature of the exhibit when designing labels that will optimally facilitate learning conversations. 
The use of questions in exhibit labels to generate explanatory conversation among science museum visitors

Conversation is a social mechanism whereby learning can be mediated through language (Wertsch, 1985); and has been used both as an instrument and an indicator of learning in both formal and informal learning environments (Leinhardt, Crowley, \& Knutson, 2002; Callanan \& Jipson, 2001; Vygotsky, 1978). Vygotsky (1978) proposed that people learn by participating in social situations using cultural tools such as language. Through language, people become familiar with and internalize ideas and concepts into complex networks of knowledge. In fact, some researchers have noted that particular aspects of language can be especially helpful in learning conversations.

The value of questions and explanations

There are many different ways of characterising conversation within learning contexts such as schools and museums. One may focus on the relative power of who is speaking, the accuracy of the content, and even the nature and relationship of questions and explanations people produce - the specific intent of this investigation. Crowley and Galco (2001) proposed that, 'explanations are a privileged category of scientific discourse' (p. 407). Their position is supported by studies in both naturalistic and laboratory settings, which suggest that explanations are useful facilitators of conceptual development. For instance, in a laboratory setting Chi, de Leeuw, Chiu, and LaVancher (1994) found that having to explain a phenomenon to oneself improved understanding of a topic. Additionally, Crowley and Jacobs (2002) investigated how parents would talk with their children about fossils in a museum. They found that 4- to 12-year-olds who heard their parents explain fossils, particularly in ways that connected to children's previous experience, were more likely to 
remember the fossil's name. In adult studies too, explanation between colleagues has been noted to play a large role in scientific discovery (Dunbar, 1995).

A complementary line of work in conversational learning has addressed the use of questions in formal and informal learning environments. Many studies have taken the Vygotskian perspective that adult questions to children can serve as a form of stimulation for cognitive development. For instance, in formal school contexts, Dillon (1989) and then Wells (1999) reported that teachers who used open-ended and thought-provoking questions tended to create atmospheres in their classrooms in which students felt safe enough to ask their own questions and participate in in-depth collaborative learning conversations. In a museum setting, Ash (2004) found that parents' questions varied depending on the ways families interacted. In her study, she found that some parents took on a teacher-like role and asked questions that they knew the answer to in an IRE pattern wherein they Initiate a question, the children Respond, and then the parents Evaluate the response. This dialogue pattern is intended to make knowledge public and confirm understanding, and has been observed in more structured learning situations in schools (Mehan, 1979; Lemke, 1990) and museums (Tran, 2006). Other parents were observed to have a more conversational style of discourse, and used questions as an invitation to further dialogue.

Another recent study examined links between children's self-report of learning, their definitions of science, and their parents' use of questions in a museum setting (Hohenstein, Callanan, \& Ash, in preparation). They found that parents who used open-ended questions, which invited further dialogue and reflection, tended to have children who said they learned more and had more sophisticated definitions of science than parents who did not use open-ended questions. Furthermore, Callanan 
and Oakes (1992) examined the 'why' questions of 3- to 5-year-old children, and noted that parents often responded to such questions with explanations of physical and social causality. That is, questions and explanations can be readily linked. Their findings suggested that explanations should be investigated in the context of other aspects of conversation, including questions, with which they appear. We have established the relevance of questions and explanations in examinations of informal conversation. What does published research say with respect to museum labels?

\section{Labels and learning behaviour}

As suggested by our discussion thus far, conversations occur between museum visitors; and these conversations potentially contribute to visitors' learning from their museum visits. Substantial formative evaluations report on visitors' use of museums' label text, though few have examined the learning behaviours associated with different types of labels in museums - specifically, the role of label texts on visitors' conversations. For instance, Bradburne (2002) provided a taxonomic inventory of label types. This work identified different types of labels that were used (e.g., textual authority, observation, variables, problems, games), but it did not examine the relation between type of label and visitor reactions to different labels. To our knowledge, no study investigates how people behave in the presence of these different types of labels.

Other studies have made note of the differences in people's conversations in the presence of labels. McManus (1989) noticed that people were reading labels, even when it appeared they had not paid attention to the label. This was apparent in the speech between visitors because people often remarked to their companions about the content of the text. McManus' work indicated that labels are important in conveying 
information to visitors, and that they are not merely peripheral components of exhibits.

Falk (1997) investigated the amount of conceptual change in child and adult visitors with and without explicit conceptual labels in two different exhibits. He found that people gained more information and spent more time at exhibits when labels explicitly presented conceptual information than when they were less explicit. In this study, participants were better able to define the major and minor messages of the exhibits when exhibits had labels that explicitly connected them to each other and to conceptual information.

Recently, a series of studies have been carried out looking at the effectiveness of different types of exhibits in generating conversation among visitors. Gutwill (2005) manipulated various aspects of hands-on exhibits (labels among other features) to engage visitors for longer periods of time than they would normally remain at an exhibit. He found that creating challenges that prompted 'What if?' questions as opposed to 'Why?' questions, promoted longer holding time among visitors, as well as different styles of engagement and more unique questions, which visitors attempted answering on their own.

\section{Current Study}

Because of the value of visitors' questions and explanations as indicators of potential learning, we sought to examine whether placing a question on an objectbased exhibit would provide impetus for people to engage in conversations that were laced with open-ended questions and explanations. Object-based exhibits offer little opportunity for hands-on interactions or manipulations that can help visitors learn about the object and its importance. Arguably, at an object-based museum exhibit, the majority of learning about the phenomenon of interest occurs through conversation, at 
least when multiple people are present. Either the visitor will read the label text or relay information about the object to their companions or perhaps, both. Thus, we proposed that object-based exhibits would be especially important to investigate with respect to the conversations that occur while visiting.

The museum we researched had previously conducted evaluations of the gallery we studied, which indicated that visitors were interested in the objects but were not picking up on the historical message of the gallery. In addition, the text that was present seemed to be particularly complicated, especially for young visitors. Therefore, we gathered data about conversations that visitors engaged in under circumstances that included the labels as they were set up, with an additional question label that was meant to promote visitor thinking about the object's historical value, and finally with both the question label and simplification of the original label text to respond to the critique that the text was too complicated. In each of these conditions, we analysed the type and quantity of visitor questions and explanations to explore whether the different label conditions effected changes in visitors' interactions at the exhibits.

\section{Method}

Data were collected at an object-based gallery in an urban science museum in the UK, which focused on the history of technological development in the UK. Three exhibits were chosen to be the objects of our study because they varied in historical era, popularity, and type of exhibit. As we discuss later, properties of the exhibits probably affect not just the content, but also the types of speech visitors utilise while attending the museum.

The first exhibit was the model of a Victorian workshop (1850), housed in a wooden and glass case, which moves like a functioning workshop when visitors press 
a button on either side of the exhibit. Contained within the workshop are miniature machine-building tools, linked to a steam engine, which drives the whole factory. Hand tools (such as files, pliers, and saws) and furniture are replicated to scale, thus further illustrating a functional Victorian-aged workshop. All four walls of the case that enclose the workshop model are made of glass, so visitors are also able to look at the multiple pieces and mechanisms that comprise the object-based exhibit from four different angles.

The second exhibit was a sectioned Austin Mini Cooper, originally displayed for the 1959 Auto Show. This is an object that is easily recognised by most British visitors and many other visitors as well due to its iconic shape and recent reproduction by BMW. It is cut in half lengthwise such that half the shell of the car is removed to allow visitors to take a close look at the interior; though the engine and axles remain intact and visible. The exposed parts of the vehicle are protected by plexiglass, which was often used as a way for some child visitors to sit on the rear axle and simulate driving the car (even though the steering wheel is on the other side). Furthermore, no rails or other protective barriers surround the object, thus enabling visitors to touch and view the car up close and from all angles.

The last exhibit focused on the effects of an atomic bomb explosion by displaying two objects: a common rice bowl, which survived the explosion in Hiroshima during World War II with only some debris affixed to its external surface; and some sand fused together as a result of an atomic bomb test. These objects are placed inside a bench with a glass top, in the major thoroughfare of the museum. The objects rest on plastic stands, and against a white background so that visitors are given access to them from a top view. 


\section{Participants}

Children and adults who entered the camera's view near the three focal exhibits were filmed for the duration of their time at each exhibit. Signs were posted at both entrances of the gallery, informing visitors that research was being conducted at some exhibits and that they had the right to participate or not in the research. Anyone who did not wish to participate could either ask to not be filmed or to have the video footage erased. No one made either request.

Three seconds seemed to be the minimum amount of time people needed for paying attention to the exhibits. Episodes lasting less than three seconds tended to be people just passing by an exhibit, rather than focusing on it. Therefore, only episodes that were at least 3 seconds were included in our analyses. In total, 839 episodes were filmed at the exhibits. Of these, 267 were at the Workshop, 427 at the Mini, and 145 at the Bowl. Looking at the different conditions (see below for descriptions), there were 346 episodes in the Current Label condition, 241 in the Added Question condition, and 252 in the Simplified Text plus Question condition.

Because we were interested in conversation and some visitors appeared on camera alone, not speaking, 183 filmed episodes were excluded from conversational analysis. An additional 192 episodes were excluded from these analyses because the participants were not speaking English. Thus, in total, we examined the conversations of 464 episodes on film, which included 132 at the Workshop, 264 at the Mini and 68 at the Bowl exhibit.

\section{Materials}

We were interested to see how people conversed at the three different exhibits. In addition, we gathered information about the effect of adding a provocative question to the exhibit. Therefore, we filmed in three different conditions: 1) Current Label 
(CL), in which we did not alter the label text the museum previously had in place. 2)

Added Question (AQ), which used the same museum label text plus a prominently placed question on a yellow sign. The question ('Why is this here?') was the same for all three exhibits and was designed to provoke thinking about the theme of the gallery, i.e., the development of technology in Britain. 3) Simplified Text plus Question (STQ), which included the same content in the museum's labels, but written in a more reader-friendly manner and placed emphasis on some of the affective/sensory factors about the exhibits (see Appendix A for examples of simplified and current label text). To simplify the text, the content of each label was listed in bullet points and then reorganised and rewritten to contain clearer referents, more logical flow from one topic to another, and a greater sense of agency through use of active voice than was present in the original text. This process was carried out in consultation with another researcher in science education who has expertise in classroom teaching. In this condition, the question in the AQ condition was also present.

All data were filmed using digital video recorders placed approximately 3 metres from the exhibits. Sound was captured using radio microphones placed on the exhibit. Video footage was transferred to 'avi' computer files for quality transcription. Procedure

Each condition was filmed for a total of two days (one weekday and one weekend). Each day of filming was conducted midday, from 10 a.m. until 1 p.m. The camera was turned on when people were present at the exhibit of interest. There was never more than one hour of data collected on any day per exhibit $(M=34 \mathrm{~min}, S D=$ $16 \mathrm{~min})$.

Additional data were gathered in the CL condition because of unusable data quality on initial collection days. Data obtained on the first day of filming were of 
substandard quality and the duration was shorter than the other days, so there were three days (two weekend) on which we filmed the CL condition. In addition, one day of filming at the Bowl exhibit in the CL condition could not be used because of damage to the tape. Thus, that exhibit was filmed a fourth time in CL but only three days of filming were analysed.

\section{Coding}

Conversations were transcribed by one individual and checked for accuracy by at least one of the authors. Afterwards, each transcript was coded for questions and informational talk.

In coding questions, each question in the transcript was selected. Coding was based on coding from Hohenstein et al. (in preparation), but changed slightly to meet the needs of this study. Generally, and as shown in Table 1, questions were coded on a spectrum of open-endedness. That is, we wanted to judge how much the question was designed (explicitly or implicitly) to draw out further conversation and encourage thinking about the exhibit material. In conditions in which the question was added to the exhibit (QA and STQ), exact repetition of the question label was omitted from analysis of the use of open-ended questions because we were interested in selfgenerated questions here. The two authors independently coded $20 \%$ of the transcripts and were sufficiently reliable, $K=0.83$. Disagreements were resolved by discussion. Each author then coded half of the remaining data.

Table 1 about here

Table 2 about here

Informational talk was coded first by selecting statements from the transcripts that related to the exhibit of interest or nearby exhibits. Utterances that had to do with the museum as a whole or which were completely unrelated to the museum were 
excluded from analysis. The coding scheme (see Table 2) was initially based on that used by Leinhardt and Crowley (2002). We added sub-categories based on the data to capture more detail. Categories ranged from identification-oriented talk to speculation. Again, each author coded $20 \%$ of the transcripts and were sufficiently reliable, $K=0.72$. Disagreements were resolved by discussion and the remaining data were split in two, with each author coding half.

\section{Results}

We examined the types of questions and explanations people used in different label conditions. To guide our analysis of the nature of visitors' utterances at the different exhibits under varying label conditions, we first examined how much time people spent and how much they talked, in general, about the exhibits (see Table 3). An Episode type (English, Solo visitor, Foreign) X Exhibit type (Workshop, Mini, Bowl) X Condition (CL, AQ, STQ) ANOVA with time, in seconds, as the dependent variable showed a significant main effect of Exhibit type, $F(2,801)=72.32, p<$ .0001 , and of Episode type, $F(2,801)=14.07, p<.0001$. Pair-wise comparisons revealed that visitors remained at the Workshop significantly longer than at either of the other two exhibits, $p$ s $<.0001$; average time spent at the Mini was also longer than at the Bowl, $p=.002$. Additionally, solo visitors spent less time at the exhibits than did either English-speaking groups or groups speaking other languages, $p \mathrm{~s}<.0001$; which is consistent with previous findings (McManus, 1987, 1988; Packer \& Ballantyne, 2005).

Table 3 about here

A second Exhibit type (Workshop, Mini, Bowl) X Condition (CL, AQ, STQ) ANOVA examining the number of exhibit-related utterances had a significant main effect of Exhibit type, $F(2,453)=24.39, p<.0001$, and showed that people, on 
average, talked more about the Workshop than about the other two exhibits, $p$ s $<$ .0001 . Because these initial analyses suggested differences in visitor conversations among the three exhibits, the following analyses were conducted separately for each exhibit and in two different ways: First we considered the frequency of different open-ended questions and informational talk at each exhibit, in each condition. Next we examined the ways people used questions and explanations in combination at the different exhibits in each condition.

\section{Questions and Explanations}

Because the average number of utterances consisting of questions and informational talk was relatively low for each interaction, we first examined collapsed categories of open-ended questions and explanations. That is, we did not initially analyse the number of utterances that were coded into each sub-category. Figure 1 shows how many open-ended questions, and Figure 2 shows how many explanations were used at each exhibit. Later we probed individual categories according to which would be likely to appear at the different exhibits.

Figures 1 and 2 about here

In looking at the Workshop, a one-way ANOVA on the number of open-ended questions showed that there were no differences across conditions, $F(2,127)=0.58$, ns. However, there was a significant difference between conditions in the number of explanations people used, $F(2,127)=3.30, p=.04$. Pair-wise comparisons indicated that people used more explanations in the AQ than in the CL condition, $p=.01$. Further probing into the sub-categories of questions revealed that the number of Right Answer questions was much lower in the STQ condition $(M=0.30)$ than in the CL or the AQ conditions $(M=0.98$ and $M=1.00$, respectively), $F(2,127)=3.88, p=.02$. Though the number of open-ended questions was not larger in the STQ condition than 
in the other conditions, people asked fewer Right Answer questions, perhaps because they could retrieve answers easily from the label. Additionally, though the number of Historical Explanations did not differ across conditions, $F(2,127)=1.73$, ns, the ANOVA conducted on the number of Causal Explanations approached significance, $F$ $(2,127)=2.83, p=.06$. Here, the pair-wise comparisons indicated a significant difference between the number of Causal Explanations in CL $(M=0.80)$ and AQ $(M$ $=1.88)$ conditions, $p=.02$.

The Mini exhibit also showed differences across conditions; however, these were largely to do with the numbers of questions, rather than numbers of explanations. The one-way ANOVA on the numbers of open-ended questions at the Mini, $F(2,263)=3.05, p=.05$, showed that people asked more open-ended questions in the AQ $(M=0.37)$ and STQ $(M=0.41)$ conditions than in the CL condition $(M=0.14), p s=.05$ and .03 , respectively. In particular, people asked more Prompt Reflection questions in these conditions ( $M \mathrm{~s}=0.29$ for AQ and 0.31 for STQ) than in the CL condition $(M=0.11), F(2,263)=3.94$, both $p s=.02$. The ANOVA on numbers of explanations did not reveal differences by condition, $F(2,263)=1.09$, ns. We were prompted to consider the frequency of the Descriptive Personal code across conditions due the nature of the Austin Mini Cooper as a prominent cultural artefact of a recent era that potentially stimulated people to recall their own experiences with cars of that model; however analyses revealed no differences, $F(2,263)=0.15$, ns.

Finally, the ANOVAs for the Bowl exhibit revealed neither differences across conditions in open-ended questions, $F(2,65)=0.02$, ns, nor in explanations, $F(2,65)$ $=0.34, \mathrm{~ns}$. The number of interactions available for analysis was much smaller at this exhibit than at the other two (68 compared to 132 at the Workshop and 264 at the Mini). This factor may have contributed to the lack of significant findings at this 
exhibit. Because there were clear emotional and historical contents at this exhibit, we specifically examined Describe Opinion, Describe Historical and Explain Historical codes. These analyses did not reveal any significant differences by condition either, with all $F_{\mathrm{s}}<1.20$, ns. ${ }^{1}$

\section{Combinations}

The previous analyses offered an indication of the number of times people used questions and explanations in various ways; but did not offer information about how people used questions and explanations in conjunction with each other. Therefore, we took a closer look at the questions in all the interactions, and noted how people responded to the different kinds of questions that were asked. Using the same codes as in the previous analyses, we examined the pairings of questions and their corresponding answers at each exhibit and in each condition separately. Unlike the previous analyses, these analyses included people's repetitions of the label so that we could examine whether visitors tried to answer the label question with a particular type of informational talk.

We first examined the conversations at the Workshop, and found that in the CL condition, there was only one pairing of an open-ended question (Prompt Reflection) with an explanation (Explain Causal); question-response pairs were predominantly closed-ended questions (Yes/No Verbal or Right Answer) with an identification or descriptive talk reply (Identification, Describe Elaboration, or Describe Dynamic). In the AQ condition, there were more open-ended question/explanation pairs (seven), most of which were Prompt Reflection or Prompt Reflection-label followed by an Explain Causal utterance. In this condition there were also a large number of Right Answer questions with Identification or Describe Elaboration answers (23). In the STQ condition, there was only one occurrence of the 
open-ended question/explanation combination, which involved the label question and an Explain Causal code. However, there were also fewer question-response combinations in this condition compared to the other conditions at this exhibit (43 in STQ, compared with 88 in CL and 90 in AQ).

At the Mini, there were remarkable differences in the number of open-ended questions/explanation pairings across the three conditions. This combination only occurred three times in the CL condition, all of which were Prompt Reflection followed by Explain Causal. In the AQ condition there were 18 such pairings, all of which included Explain Causal codes, and 16 of those were preceded by either a Prompt Reflection (10) or a Prompt Reflection-Label (6). These open-ended question/explanation pairings constituted $28 \%$ of the total number of question/response combinations. The number of open-ended questions followed by explanations was lower for the STQ condition (5), with 4 of these being Explain Causal, which followed Prompt Reflection-Label.

The Bowl exhibit, unsurprisingly due to low overall numbers, did not show very many combinations of questions and responses at all. It is tempting to report that there were more open-ended question/explanation pairings in the STQ condition because there were three as opposed to one in each of the other conditions. However, the numbers were really too small to be meaningful.

A striking pattern appeared when we examined the number of questions that went unanswered at each exhibit. It seemed that more questions remained unanswered than received answers on many occasions. For instance, there were 159 questions asked at the Workshop in the AQ condition, but 69 of them were unanswered, seven of which were open-ended questions. Of course, many of the unanswered questions may have been asked in a rhetorical sense or could be answered nonverbally. Table 4 
shows the numbers of combinations and unanswered questions in each condition at each exhibit.

Table 4 about here

Examining conversations in the specific context of each exhibit

Complexity of the exhibits. While all the exhibits under scrutiny in this study are object-based, the featured objects varied in physical complexity and selfexplanatory nature. The Workshop is most physically complex in that the moving parts of the machines including the bands, lathes, and cogs are visible to the visitors so that they can witness how it functions when the machines are activated. However, this object is also perhaps the most self-explanatory, compared to the other two. The model's moving parts show how the bands, lathes, and cogs move together to work the machine such that visitors can explain the mechanism through their observations, which is likely the intention of the exhibit.

Arguably, the Mini and the Workshop are equally complex - the section on display is closed off with plexiglass so that visitors may see the inside of the car but not sit in it, and the motor is shown in its entirety. The Mini might be seen as less selfexplanatory than the Workshop in that visitors are challenged with imagining how the transverse placement of the engine enabled the cars' designers to make the vehicle smaller while also creating more interior capacity. From this understanding, visitors may realize that this design change revolutionized car making thereafter.

Finally, the Bowl is the least physically complex exhibit, displaying the surviving rice bowl and fused sand. This exhibit is also the least self-explanatory, compared to the other two. Here, visitors are shown two simple objects while faced with conceptualizing the power of an atomic bomb explosion to fuse sand grains juxtaposed with a ceramic bowl that survived such an explosion used in wartime that 
destroyed a city. In addition to these varied details that distinguished the three exhibits, visitors' conversations with our guiding question differed in their emphases.

Emphases of the conversations. The guiding 'Why is this here?' question was placed in a visibly prominent place on the exhibits compared to their existing labels. On the Workshop, the question was placed next to the button on the wooden portion of the exhibit, whereas the text label was on a separate stand next to the exhibit. We placed the question on the plexiglass of the Mini while the text label was situated in front of the plexiglass. For the Bowl, the question was affixed on the glass covering directly above the bowl; the exhibit's label was immediately next to the bowl and also had a picture of the mushroom cloud created by an atomic bomb explosion.

The questions and informational talk visitors produced in the presence of our guiding question related to different aspects of the exhibits. At the Workshop, most explanations were directed at the mechanisms driving the machinery, as suggested by the following excerpt between an adult female (1F, about 40 years old) and two male children (1MC \& 2MC, both 8-10 years old) during the AQ condition:

\begin{tabular}{|c|c|c|c|}
\hline $\begin{array}{l}\text { SPEAKER } \\
1 \mathrm{MC}\end{array}$ & $\begin{array}{l}\text { UTTERANCE } \\
\text { Why is this here? }\end{array}$ & $\begin{array}{c}\text { QUESTION } \\
\text { Prompt reflection- } \\
\text { Label }\end{array}$ & TALK \\
\hline $1 \mathrm{MC}$ & Why is it here? & Prompt reflection & \\
\hline $1 \mathrm{~F}$ & I don't know. Let's press & & \\
\hline $2 \mathrm{MC}$ & Let's press now & & \\
\hline $1 \mathrm{MC}$ & Hey is that moving? & Yes/No Verbal & \\
\hline $1 \mathrm{~F}$ & Oh it is moving, yeah. & & $\begin{array}{l}\text { Describe } \\
\text { dynamics }\end{array}$ \\
\hline $1 \mathrm{~F}$ & $\begin{array}{l}\text { So that turns that, so } \\
\text { then that turns this and } \\
\text { this turns that. }\end{array}$ & & Explain causal \\
\hline $1 F$ & $\begin{array}{l}\text { That's the fire. That used } \\
\text { to be the fire. }\end{array}$ & & $\begin{array}{l}\text { Describe } \\
\text { historical }\end{array}$ \\
\hline $1 F$ & $\begin{array}{l}\text { This one's going there } \\
\text { and down under there. }\end{array}$ & & Explain causal \\
\hline $1 F$ & $\begin{array}{l}\text { That's...you see that } \\
\text { one's going. }\end{array}$ & & Identify \\
\hline $1 F$ & $\begin{array}{l}\text { That's turning this one } \\
\text { which is turning that, } \\
\text { innit? }\end{array}$ & $\begin{array}{c}\text { Yes/No Verbal, } \\
\text { Tag }\end{array}$ & Explain causal \\
\hline
\end{tabular}


This pattern, wherein an open-ended question coupled with the moving parts prompted explanations about the machinery, was more prominent in the AQ condition than in the other two conditions, as suggested by our findings above. Our guiding question may have directed visitors' attention to the button that mechanized the exhibit, which resulted in explanations of the mechanism driving the factory occurring more frequently with the presence of the added question.

In contrast, at the Mini, many visitors remarked on the fact that only half of the car was present, and some even asked questions enquiring why the car has been cut in half. This type of query was asked more often when our guiding question was placed on the plexiglass. Furthermore, their responses to ours and their own questions tended to explain why they believed the car was cut in half, as illustrated by the following conversation between a woman $(1 \mathrm{~F}$, about 35 years old) and two boys (1MC, approximately 5 years old \& $2 \mathrm{MC}$, about 3 years old):

\begin{tabular}{|c|c|c|c|}
\hline SPEAKER & UTTERANCE & QUESTION & TALK \\
\hline $1 \mathrm{~F}$ & What have they done?.. & Clarification & \\
\hline $1 F$ & $\begin{array}{l}\text { Why is this here? } \\
\text { reading }\end{array}$ & $\begin{array}{l}\text { Prompt reflection- } \\
\text { Label }\end{array}$ & \\
\hline $1 \mathrm{MC}$ & I don't know & & \\
\hline $1 \mathrm{~F}$ & $\begin{array}{l}\text { It's a Mini that's been cut } \\
\text { in half }\end{array}$ & & $\begin{array}{l}\text { Describe } \\
\text { elaborate }\end{array}$ \\
\hline $1 \mathrm{MC}$ & Why? & Prompt reflection & \\
\hline $1 \mathrm{~F}$ & $\begin{array}{l}\text { Cos it's to give you a } \\
\text { cross section of a car }\end{array}$ & & Explain causal \\
\hline $2 \mathrm{MC}$ & $\begin{array}{l}\text { I don't see what's inside } \\
\text { the car } \\
\text { And there's wires }\end{array}$ & & $\begin{array}{l}\text { Describe action } \\
\text { Identify }\end{array}$ \\
\hline \multicolumn{4}{|c|}{ The focus of conversations like this tended to be on the reason for removing part of } \\
\hline \multicolumn{4}{|c|}{ the car's exterior, and identifying what was made observable as a result. While the } \\
\hline gine and axle & vere intact and visible, an & full label text ga & ails \\
\hline
\end{tabular}


Finally, at the Bowl, informational talk tended to derive from the text label as visitors identified the objects on the display, described the fused materials, and explained the objects' origins as dating back to an atomic bomb explosion. For example, two male children (1MC \& 2MC) who were both about 14-15 years old engaged in the following conversation during the STQ condition:

\begin{tabular}{|c|c|c|c|}
\hline SPEAKER & UTTERANCE & QUESTION & TALK \\
\hline $1 \mathrm{MC}$ & $\begin{array}{l}\text { Massive bombs, weren't } \\
\text { they? }\end{array}$ & Yes/No Verbal, Tag & $\begin{array}{l}\text { Describe } \\
\text { elaborate }\end{array}$ \\
\hline $2 \mathrm{MC}$ & Fuel san, oh fused sand & & Identify \\
\hline $1 \mathrm{MC}$ & $\begin{array}{l}\text { Oh my god did you see } \\
\text { that? }\end{array}$ & Yes/No Behaviour & \\
\hline $1 \mathrm{MC}$ & $\begin{array}{l}\text { When they detonated the } \\
\text { first } A \text { bomb the heat } \\
\text { made all the glass in the } \\
\text { desert fuse together and } \\
\text { make green glass. }\end{array}$ & & Explain causal \\
\hline
\end{tabular}

The information that each boy expressed came from the exhibit label. Compared to the other two exhibits under scrutiny in this study, the physical simplicity of this display, that is, a bowl and fused sand on a plastic plate, would render talk about the objects challenging without more information from the exhibit label. In fact, the percentage of visitors' open-ended questions and explanations in the current label condition were 16.7 and 11.4 respectively. When the guiding question was added the percentages dropped to 9.4 and 3.8 respectively. Though the differences were not significant, they seem to indicate a trend toward the use of fewer open-ended questions and explanations in the presence of the guiding question.

Discussion

\section{Summary of findings}

Our findings suggest that guiding questions as a part of exhibit labels affect visitors' conversations at object-based exhibits. Analyses of the numbers of openended questions and explanations at each exhibit indicated that people used more 
explanations, in particular more Causal Explanations, at the Workshop exhibit when there was a guiding question ('Why is this here?') placed on the exhibit. There was also a tendency to respond to open-ended questions with explanatory answers more often when the guiding question was present. At the Mini exhibit, the pattern was somewhat different. Rather than a change in frequency of explanations offered, people tended to ask more open-ended questions when the guiding question was added to the exhibit and when the text was simplified in the presence of the added question than in the current label situation. Whereas more open-ended questions were asked in the condition where simplified text replaced the current label, this condition did not seem to inspire people to answer open-ended questions with explanations as often as the guiding question alone did. Finally, differences between label conditions at the Bowl exhibit were minimal. Again, there were fewer visitors to this exhibit than there were to the other exhibits, perhaps contributing to the lack of differences.

Overall, there appeared to be two results of interest. First, the guiding question was helpful for increasing explanations and open-ended questions, two types of talk shown to be beneficial to cognitive learning (Chi et al, 1994; Dillon, 1989; Dunbar, 1995; Wells, 1999). However, adding the question did not provide the same responses at each exhibit. In particular, conversations at the Bowl exhibit did not appear to change as a result of providing the question, whereas the question seemed to generate different types of positive learning conversations at the Mini and the Workshop. Second, it was puzzling that the simplification of label text plus the guiding question should seem to generate fewer indicators of learning conversation than adding the question alone would do. Each of these results will be discussed below. 


\section{Matching of Question to Exhibit}

Our guiding 'Why is this here?' question did not stimulate equal gains in open-ended questions and explanations across all three object-based exhibits; such that more explanations were offered at one exhibit while more open-ended questions were asked at another; and there was no change at the third. To make sense of such disparities, we reflect on the relation between the added question and each exhibit, and offer two possible explanations. Though the lack of differences between conditions at the Bowl exhibit may have been due to a small number of visitors relative to the other exhibits we investigated, for purposes of this discussion, we will assume that there would be no differences if we had a larger group of visitors to follow.

First, we consider that the disparities in visitors' conversations may be attributed to the qualitative nature of the exhibits, and thus propose that much like interactive exhibits, affordances from object-based exhibits are affected by features that make up the exhibit (Allen, 2004; Gutwill, 2005). As the descriptions of the exhibits offered in the previous section suggested, the featured objects differed in physical complexity and self-explanatory nature; which may affect the ways that visitors were 'asked' to engage in conversation about them. Similarly, Eberbach and Crowley (2005) reported different frequencies and levels of visitors' explanations at three kinds of objects (a living, virtual, and model of a plant) exploring the same concept: pollination. Furthermore, Gilbert and Stocklmayer (2001) determined that varying interactive model designs encouraged different behaviours among visitors, and thus the level of interaction and learning that could take place.

Consequently, the same guiding question we placed on the three different exhibits may have led to variability in responses from the visitors. For example, the 
intricate details of the tools and movable machinery at the Workshop prompted visitors to talk about the machines they observed in a way that explained the mechanism because the machines were moving right in front of them. Unlike the Workshop, the Mini did not display moving parts. Instead, visitors' explanations and open-ended questions tended to refer to the oddity of the vehicle having been cut in half. While at the Bowl, the challenge was to reflect on the significance of the surviving rice bowl and the power of a nuclear explosion; the historical and current importance of which might not necessarily prompt conversation while at the exhibit.

Second, we take into account possible ways in which visitors interpreted our guiding question. For instance, at the Workshop, placement of the added question next to the button that activated the machinery may have been interpreted as enquiring about the purpose of the button. In which case, visitors may have offered explanations about the mechanics of the exhibit because pushing the button set the machines in motion; and thus, provided more explanatory talk in the presence of the question than without. Whereas at the Mini, our guiding question may have been construed by many visitors as, 'why has this been cut in half?', which corresponded with the predominance of explanations on the reason for displaying a sectioned vehicle. Interestingly, our question appeared to motivate a greater number of open-ended questions, even if it did not inspire visitors to provide more explanations.

Aside from the possibility that we did not have enough data to make meaningful statistical analyses at the Bowl, our guiding question may have been understood as asking visitors to explain the survival of the bowl, how the survival of bowl was historically significant, or even how the fused sand and rice bowl were related. Though visitors may have been willing and capable of responding to such questions, the query may have stimulated introspective reflection rather than verbal 
communication; or visitors may not have wanted to contemplate such a topic in the context of the gallery. Thus, irrespective of the exhibit designers' original intents, our findings suggest that a guiding question directed visitors' attention to particular features of the objects, which then affected the ways in which visitors talked about the objects.

\section{Simplification of label text}

We expected the simplified label text to facilitate visitors' learning conversations about the exhibits. In contrast, the condition that included the highest number of learning conversation indicators was the added question (without the simplification of current labels). We offer three possible reasons for this result. First, the text in the simplified labels could be difficult to discern because it was printed in grey colour (as compared with black in the other conditions); second, from the visitors' perspective, the text might not be more simple to read than the current label text; and third, again from the visitors' perspective, the text was so simple that they did not feel the need to discuss it. Having a lighter font in the simplified text plus question condition than in the other two conditions created a limitation to the study. Without collecting more data with a new darker version of the simplified label text, we cannot know whether the visibility of the text contributed to the results we obtained here. Additionally, though we have not conducted surveys to judge the readability of each text, we maintain that the text in the simplified label condition is, indeed, easier to understand than the current label text. Again, without further data collection, we cannot determine whether the text was so simple it became less worthy of discussion. Future research should investigate the way people speak at object exhibits in the presence of simple and complicated text without the addition of a guiding question. 


\section{Conclusions}

This is the first study of which we are aware that investigates, in depth, how text on exhibit labels might contribute to questions visitors ask and explanations they offer at an object-based science museum. As indicated by others (e.g., Dillon, 1989; Chi et al., 1994; Crowley \& Jacobs, 2002; Ash, 2004; Hohenstein et al., in preparation), questions and explanations are important elements in learning conversations. Our findings suggest that adding a guiding question to an exhibit may promote more open-ended questions and explanations among visitors, though not in a uniform way. Similar to interactive exhibits (Allen, 2004; Gilbert \& Stocklmayer, 2001), object-based exhibits may encourage visitors to engage with and converse about the objects in different ways depending on the nature of the object (Eberbach \& Crowley, 2005). Moreover, a question in the label text may serve as a prompt to focus visitors' attention, and thus conversations, toward particular characteristics of the objects. Guiding questions as a part of label text at object-based exhibits can potentially stimulate enquiry and reflection. However, the questions should be written such that they take into account the nature of the objects, and thus the ways in which visitors are likely to engage with the object. For instance, an object like the Hiroshima Bowl is neither physically complex nor self-explanatory despite being thoughtprovoking. It may be more stimulating for visitors if the guiding question is focused on a concept or position, such as one that enquires about the significance of the atomic bomb. Consequently, matching the type of question to stimulate thought and conversation to the complexity of the object may be more important than devising generally provocative labels. 


\section{References}

Allen, S. (2004). Designs for learning: Studying science museum exhibits that do more than entertain. Science Education, 88, S17-S33.

Ash, D. (2004). Knowing what to ask: Questions as invitations to learning at dioramas. Curator, 47, 84-100.

Bradburne, J.M. (2002). Museums and their languages: Is interactivity different for fine art as opposed to design? Paper presented at the Interactive Learning in Museums of Art conference. London, May.

Callanan, M. \& Jipson, J. (2001). Explanatory conversations and young children's developing scientific literacy. In K. Crowley, C. Schunn, \& T. Okada (eds.), Designing for science: Implications for everyday, classroom, and professional settings (pp. 21-49). Mahwah, NJ: Lawrence Erlbaum Associates.

Callanan, M. \& Oakes, L. (1992). Preschoolers' questions and parents' explanations: Causal thinking in everyday activity. Cognitive Development, 7, 213-233.

Chi, M., de Leeuw, N., Chiu, M., \& LaVancher, C. (1994). Eliciting self-explanations improves understanding. Cognitive Science, 18, 439-477.

Crowley, K. \& Galco, J. (2001). Everyday activity and the development of scientific thinking. In K. Crowley, C. Schunn, \& T. Okada (eds), Designing for science: Implications for everyday, classroom, and professional settings (pp. 393-413). Mahwah, NJ: Lawrence Erlbaum Associates.

Crowley, K. \& Jacobs, M. (2002). Building islands of expertise in everyday family activity. In G. Leinhardt, K. Crowley, \& K. Knutson (Eds.), Learning conversations in museums (pp. 333-356). Mahwah, NJ: Lawrence Erlbaum Associates.

Dillon, J.T. (1989). The practice of questioning. London: Routledge. 
Dunbar, K. (1995). How scientists really reason: Scientific reasoning in real-world laboratories. In Sternberg \& Davidson (eds), The nature of insight. Cambridge, MA: MIT Press.

Eberbach, C. \& Crowley, K. (2005). From living to virtual: Learning from museum objects. Curator, 48, 317-338.

Falk, J. (1997). Testing a museum exhibition design assumption: Effect of explicit labeling of exhibit clusters on visitor concept development. Science Education, 81, 679-687.

Gilbert, J.K. \& Stocklmayer, S. (2001). The design of interactive exhibits to promote the making of meaning. Museum Management and Curatorship, 19, 41-50.

Gutwill, J. (2005). Observing APE. In T. Humphrey, J. Gutwill, and the Exploratorium Team (eds), Fostering Active Prolonged Engagement: The art of creating APE exhibits (pp. 5-21). San Francisco: Exploratorium.

Hohenstein, J., Callanan, M., \& Ash, D. (in preparation). Exploring the links between parent-child questions and children's ideas about science.

Leinhardt, G. \& Crowley, K. (2002). Objects of learning, objects of talk: changing minds in museums. In S. Paris (ed), Perspectives on object-centered learning in museums (pp. 301-324). Mahwah, NJ: Lawrence Erlbaum Associates.

Leinhardt, G., Crowley, K., \& Knutson, K. (2002). Learning conversations in museums. Mahwah, NJ: Lawrence Erlbaum Associates.

Lemke, J. L. (1990). Talking science: language, learning, and values. Westport CT: Albex Publishing.

McManus, P. (1987). It's the company you keep: The social determination of learning-related behavior in a science museum. The International Journal of Museum Management and Curatorship, 6, 263-270. 
McManus, P. (1988). Good companions: More on the social determination of learning and behavior in a science museum. International Journal of Museum Management and Curatorship, 7, 37-44.

McManus, P. (1989). Oh, yes, they do: How museum visitors read labels and interact with exhibit texts. Curator, 32, 174-189.

Mehan, H. (1979). Learning lessons: Social organizations in the classroom. Cambridge MA: Harvard University Press.

Packer, J. \& Ballantyne, R. (2005). Solitary vs. shared learning: Exploring the social dimension of museum learning. Curator: The Museum Journal, 48, 177-192.

Tran, L. U. (in press). Teaching science in museums: The pedagogy and action of museum educators. Science Education.

Vygotsky, L. (1978). Mind in society: The development of higher psychological processes. Cambridge, MA: Harvard University Press.

Wells, G. (1999). Dialogic inquiry: Toward a sociocultural practice and theory of education. Cambridge: Cambridge University Press.

Wertsch, J. (1985). Vygotsky and the social formation of mind. London: Harvard University Press. 
Appendix A

Label Text

\section{Workshop}

\section{Current Label}

Model of Machine Workshop

This model, made between 1850 and 1880, gives a good overall impression of a machine shop of the period driven by steam. The model includes the types of machines that might have been seen in a workshop undertaking general machinebuilding during that time. However, it would have been unusual to find the steam engine in the workshop itself. Usually the engine would have been in a separate room, or at least divided from the workshop by a partition.

Individual machine tools are positioned to receive power from line-shafts driven by the engine, some through countershafts. This arrangement persisted until well into the twentieth century, until the general adoption of machine tools driven by individual electric motors. Some small lathes are shown being worked by treadle, which was quite common since it afforded more flexibility than if driven from the line-shaft. There was much work to be done by hand at this time and in this class of work, whether rough preparation of parts before machining or delicate finishing, which explains the need for a number of fitters' benches with vices. The enclosed area represents a store for small tools and drawings.

Source: A Graham. Inv. 1927-1051 


\section{Simplified Label}

Model of Machine Workshop

What would a machine workshop have been like between 1850 and 1880 ? This model gives us some idea. The machines shown here would have been used to build other machines.

Working in such a shop would have been very noisy. The source of power was a steam engine, which usually would have been in a separate room. The steam engine drives a line-shaft in the ceiling. This is connected to the machines by belts or countershafts. Only in the $20^{\text {th }}$ Century did electric motors to individually run machines become more common.

If you look carefully, you can see that some of the machines would have been worked by foot using a treadle. It was easier to control.

Nevertheless, a lot of work was still done by hand - either for rough preparation or finishing items by hand. Consequently there are a lot of benches for the workmen (no women would have worked in the factory) who were called fitters. They would have needed a lot of tools and drawings. These would have been stored in the enclosed area.

\section{$\underline{\text { Mini }}$}

\section{Current Label}

Sectioned Mini, 1959

When first introduced in 1959 the BMC Mini was a unique concept in motor car design. This sectioned example was prepared by the company for the launch at the 1959 Motor Show and shows how the designer, Alec Issigonis, achieved so much space in a car only 10 feet $(3.04 \mathrm{~m})$ long. The key to his achievement was turning the engine sideways and integrating it with the gearbox and final drive. 
BMC made the Mini in identical Austin and Morris versions (this is a Morris). In design terms the car became extraordinarily influential and soon the compact transverse front engine layout became standard for smaller cars from all makers. However, it is unlikely that BMC and its successors made significant profits from this ground-breaking design.

1962-192 (British Motor Corporation)

\section{Simplified Label}

Sectioned Mini, 1959

The Mini revolutionised motor design. The designer, Alec Issigonis, was the first to save space by turning the engine sideways and integrating it with the gearbox and driving the front wheels. This allowed for a relatively large interior space in the 10 foot $(3.04 \mathrm{~m})$ long car, clearly visible here. Soon small cars from all makers were using this engine layout. This sectioned example was prepared by the British Motor Company for the Mini's introduction at the 1959 Motor Show.

\section{Hiroshima Bowl}

\section{Current Label}

1. Bowl from Hiroshima, c. 1945

This porcelain bowl was found among the ruins of Hiroshima after the atomic bomb explosion on 6 August 1945, which helped end the Second World War. It is a typical piece of Japanese tableware, used for pickles and chutneys. The heat of the nuclear explosion caused the glaze of the bowl to melt, and it has fragments of brick and other pottery embedded in it. The family which used the bowl would have been obliterated 
by the blast; over 78,000 people were killed immediately and a further 50,000 were to die soon afterwards. A second bomb was dropped three days later, on Nagasaki, which killed at least 60,000 people.

Source: P A Boase. Inv. 1984-663

\section{Fused Sand from Atomic Bomb Test, 1945}

The first atomic bomb was exploded at a desert site near Alamogordo, New Mexico, in a test called Trinity. The ferocious heat generated by the blast fused the desert surface into a greenish glassy substance and melted the 30 metre steel tower on which the bomb had been placed. Even the scientists who had worked on the Manhattan Project, the programme to develop the bomb, were stunned by the power of the test. 'When the sinister and gigantic cloud' rose over the desert, their leader, Robert Oppenheimer, recalled a line from the sacred Hindu text, the Bhagavad-Gita: 'I am become Death, the shatterer of worlds'.

Source: CS Smith Inv. 1931-158

\section{Simplified Label}

1. Bowl from Hiroshima, c. 1945

This is no ordinary bowl. It was found amongst the ruins of Hiroshima after the atomic bomb explosion on 6 August, 1945. The bowl's glaze melted and pieces of debris stuck to it in the heat of the blast. But the bowl remains otherwise intact. In contrast, the family who owned this bowl were no doubt killed in the blast.

The Second World War ended in 1945, soon after the atomic bomb was dropped on Hiroshima on 6 August. Over 78,000 people died immediately with 50,000 more dead before long. Three days later a second bomb was dropped on Nagasaki, killing at least 60,000 people. 
2. Fused Sand from Atomic Bomb Test, 1945

'I am become Death, the shatterer of worlds.' That was the line from the sacred Hindu text, the Bhagavad-Gita, that Robert Oppenheimer recalled upon witnessing Trinity, the test of the first atomic bomb. Dr. Oppenheimer headed the Manhattan Project, which developed the bomb. As can be seen in this sample, the blast's heat fused the desert surface (near Alamogordo, New Mexico) into a greenish glassy substance. It also melted the 30 metre steel tower that had held the bomb. 
Acknowledgements

Jill Hohenstein and Lynn Uyen Tran, Department of Education and Professional Studies, King's College London.

This project was funded by a Seedcorn grant from the Department of Education and Professional Studies to the first author as well as NSF grant number 0119787 for the Center for Informal Learning and Schools. We thank Jonathan Osborne for contributing to initial conversations about this project and Harriet Tennenbaum and two anonymous reviewers for comments on earlier versions of this paper. We are grateful for the help of Valerie Bontrager, Ellen McCallie and Robin Meisner in collecting these data. We would also like to thank Marnie Freeman for her aid in transcription, and Alex Burch and all the museum staff for facilitating our data collection.

Correspondence concerning this manuscript should be addressed to Jill Hohenstein, Department of Education and Professional Studies, King's College London, Waterloo Road, London, SE1 9NH, United Kingdom. Electronic mail can be sent to [jill.hohenstein@kcl.ac.uk] 


\section{Footnotes}

1. We also conducted all these statistical analyses on the arcsine transformed ratios of open-ended questions to total questions and explanation to total informational talk. However, though the patterns of differences between means were similar for each exhibit in both open-ended questions and explanations, the ANOVAs were not significant for any analysis. Analyses in ratios seem to include higher relative variances compared to analyses on raw numbers of utterances. 
Table 1. Question coding scheme.

Code

Description

Example

Open-ended

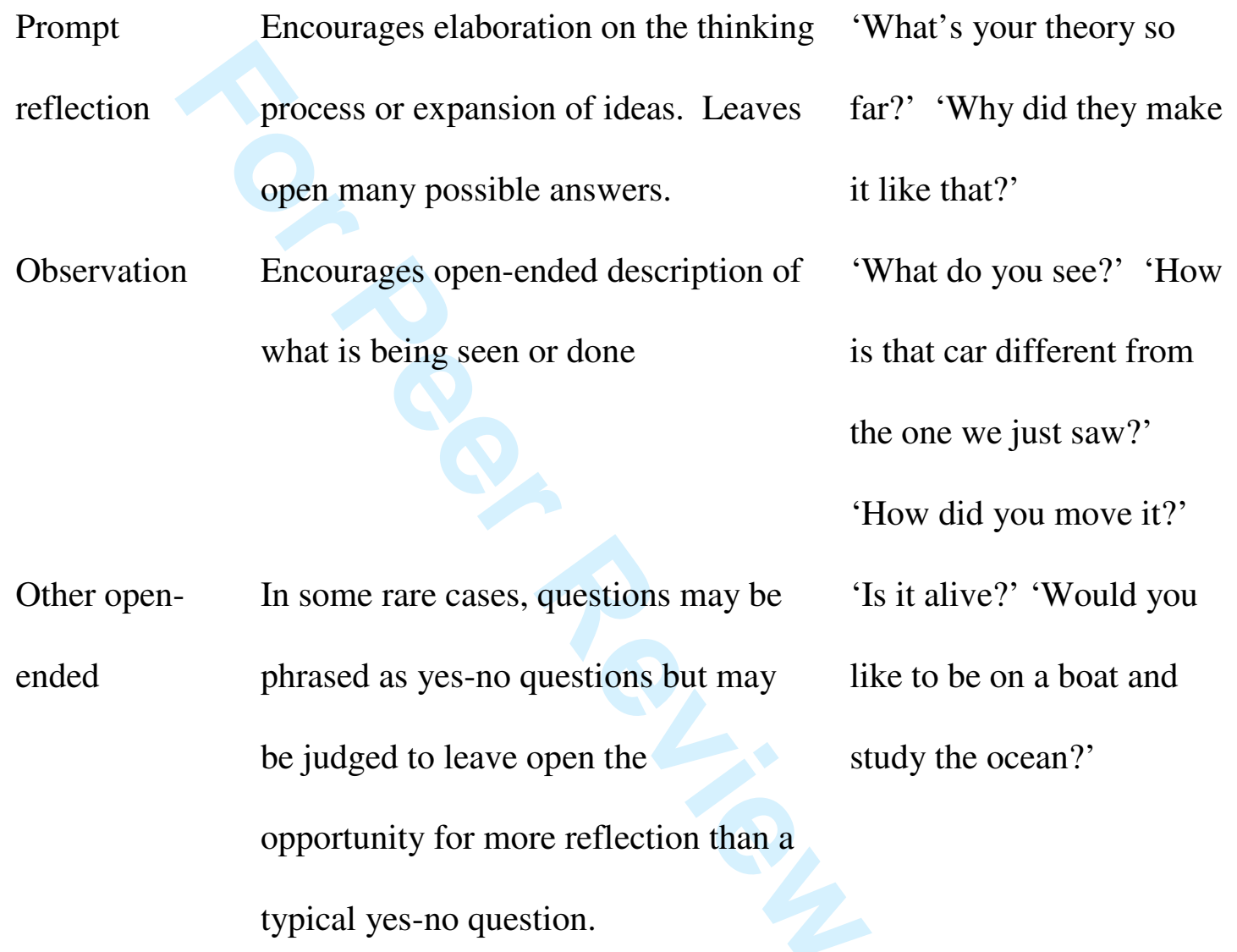

\section{Closed-ended}

Yes/No Don't necessarily call for verbal

'Can you see it?' 'Do you

Behavioural answers but that provide an opening want to touch it?'

for the other to engage physically with

exhibit (includes observing)

Yes/No Verbal Provide an opening for the other to

'Do you think it's a participate verbally by calling for brief factory?' verbal answers such as 'yes' or 'no'. 
Yes/No Provide an opening for the other to

'That's interesting, isn't

Verbal-Tag

participate verbally as above but by

it?' 'That would be fun,

use of a tag question. These take form wouldn't it?'

of a statement followed by a question

phrase.

Right answer Call for a factual answer.

'What's that bit called?'

\section{Clarification \\ Asks for clarification of something that} has been said. This category should be limited to cases where the questioner is misunderstanding, verifying, or checking on understanding.

\section{Routine}

Routine
Seem more about activity and routine than about the exhibits
'How many wheels do you see?' 'What's that?'

'What?' when person did not hear correctly or repeating a question already asked that hasn't been answered 'Ready?' 'Do you have to go to the bathroom?' 
Table 2. Informational Talk coding scheme.

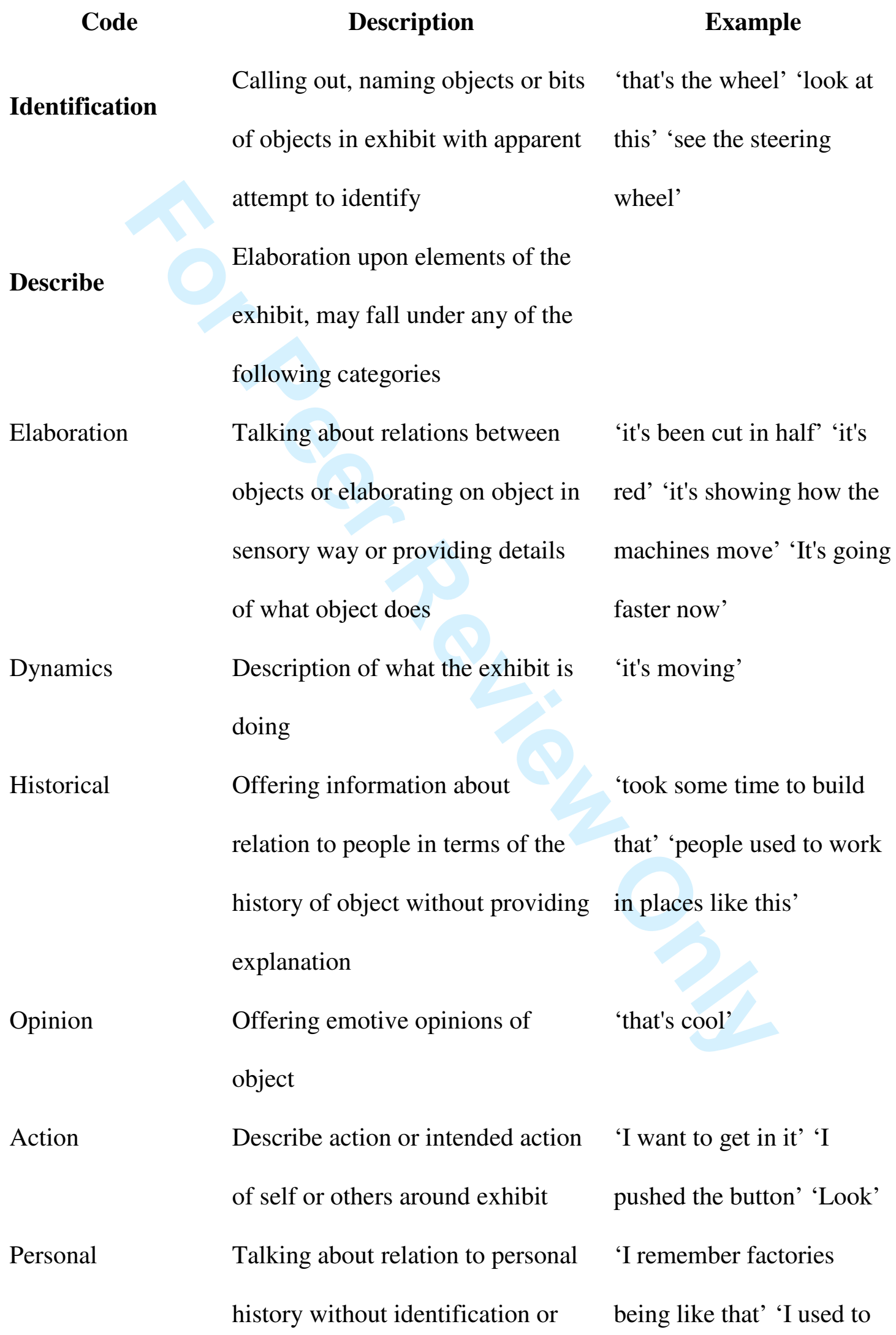




\section{Explain}

To make clear the cause, origin, or

reason of; to account for. (OED)--

any of the following codes must

include some form of explanation

as defined here but can be

differentiated by different

categories

Agentive

Talk about agent (person or

'I made it go' 'if you push

object) that causes exhibit to move

the button, it makes it go'

'it moves by itself'

Historical

Talk of how things used to be

'this is the way they used

done or the origins of a given

to make tools'

object or aspect of an object

through historical reference or

implicit historical reference

Personal

Pointing out how something about

'I learned to drive in one o

the object/exhibit is influential in

these'

individual's personal development

Causal

Talk about causal elements in

'that runs the factory'

object, causes can be mechanical

as when one thing in exhibit

makes another do something 


\section{Speculation}

Offering a prediction about what if you made this full sized

something would be like if it it would be 20 metres

something else had changed. This long'

might be on the order of small-

scale event like button-pushing or

large-scale like the end of World

War II 


\section{ENGLISH}

Exhibit

Workshop

$71.80(3.50)$

$12.58(0.75)$

Mini

31.95 (2.46)

$6.44(0.53)$

Bowl

$44.36(5.00)$

$6.11(1.06)$

\section{Condition}

CL

AQ

STQ

SOLO

Exhibit

Workshop

$47.90(4.69)$

Mini

$17.78(5.23)$

Bowl

$25.20(5.94$

\section{Condition}

CL $27.40(4.57)$

AQ

$28.97(6.25)$

STQ

34.52 (4.97)

\section{FOREIGN}

Exhibit 
Workshop

$77.16(4.62)$

Mini

$24.50(4.11)$

Bowl

$44.12(6.96)$

\section{Condition}

CL

$49.57(4.91)$

AQ

$45.22(5.86)$

STQ

$50.99(5.31)$ 

each exhibit

Exhibit and PR PR- OB OO YNB YNV YNVT RA CL Total Condition Label

\section{Workshop}

$\begin{array}{llllllllllll}\mathrm{CL} & 4 & 0 & 2 & 0 & 7 & 10 & 16 & 16 & 3 & 58\end{array}$

$\begin{array}{lllllllllll}\text { AQ } & 4 & 3 & 0 & 0 & 10 & 11 & 21 & 6 & 14 & 69\end{array}$

$\begin{array}{lllllllllll}\text { STQ } & 4 & 3 & 1 & 0 & 15 & 3 & 6 & 3 & 5 & 40\end{array}$

Mini

$\begin{array}{lllllllllll}\text { CL } & 1 & 0 & 0 & 0 & 2 & 1 & 1 & 3 & 2 & 10\end{array}$

$\begin{array}{lllllllllll}\text { AQ } & 1 & 1 & 0 & 0 & 1 & 0 & 2 & 6 & 1 & 12\end{array}$

$\begin{array}{lllllllllll}\text { STQ } & 0 & 0 & 0 & 0 & 6 & 3 & 1 & 3 & 1 & 14\end{array}$

Bowl

$\begin{array}{lllllllllll}\mathrm{CL} & 2 & 0 & 0 & 1 & 7 & 7 & 6 & 8 & 0 & 31\end{array}$

$\begin{array}{lllllllllll}\text { AQ } & 10 & 14 & 3 & 0 & 9 & 9 & 17 & 10 & 3 & 75\end{array}$

$\begin{array}{lllllllllll}\text { STQ } & 7 & 11 & 1 & 3 & 3 & 8 & 10 & 8 & 1 & 50\end{array}$


Figure Captions

Figure 1. Visitors' mean number of open-ended questions at each exhibit in each condition.

Figure 2. Visitors' mean number of explanations at each exhibit in each condition. 


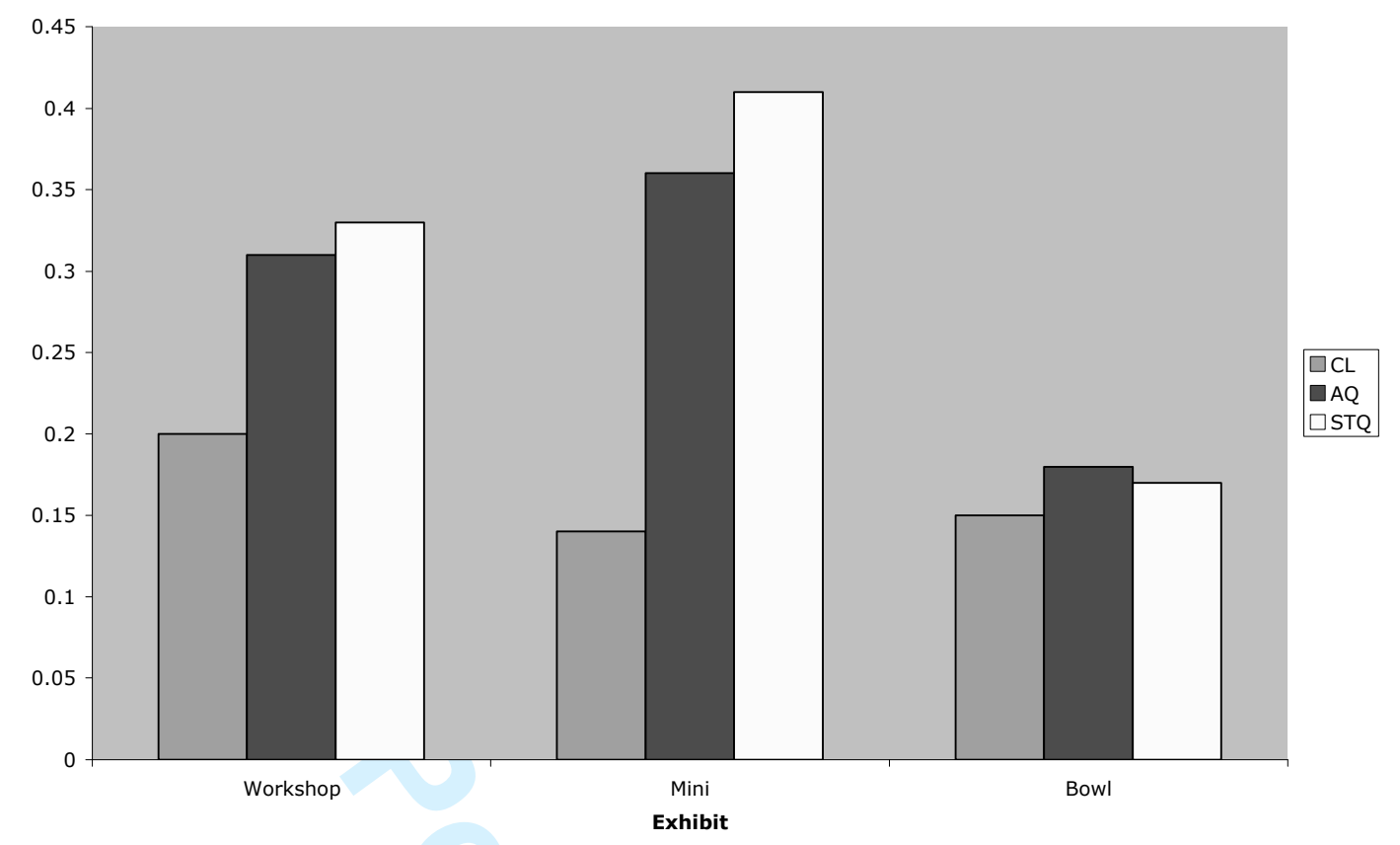




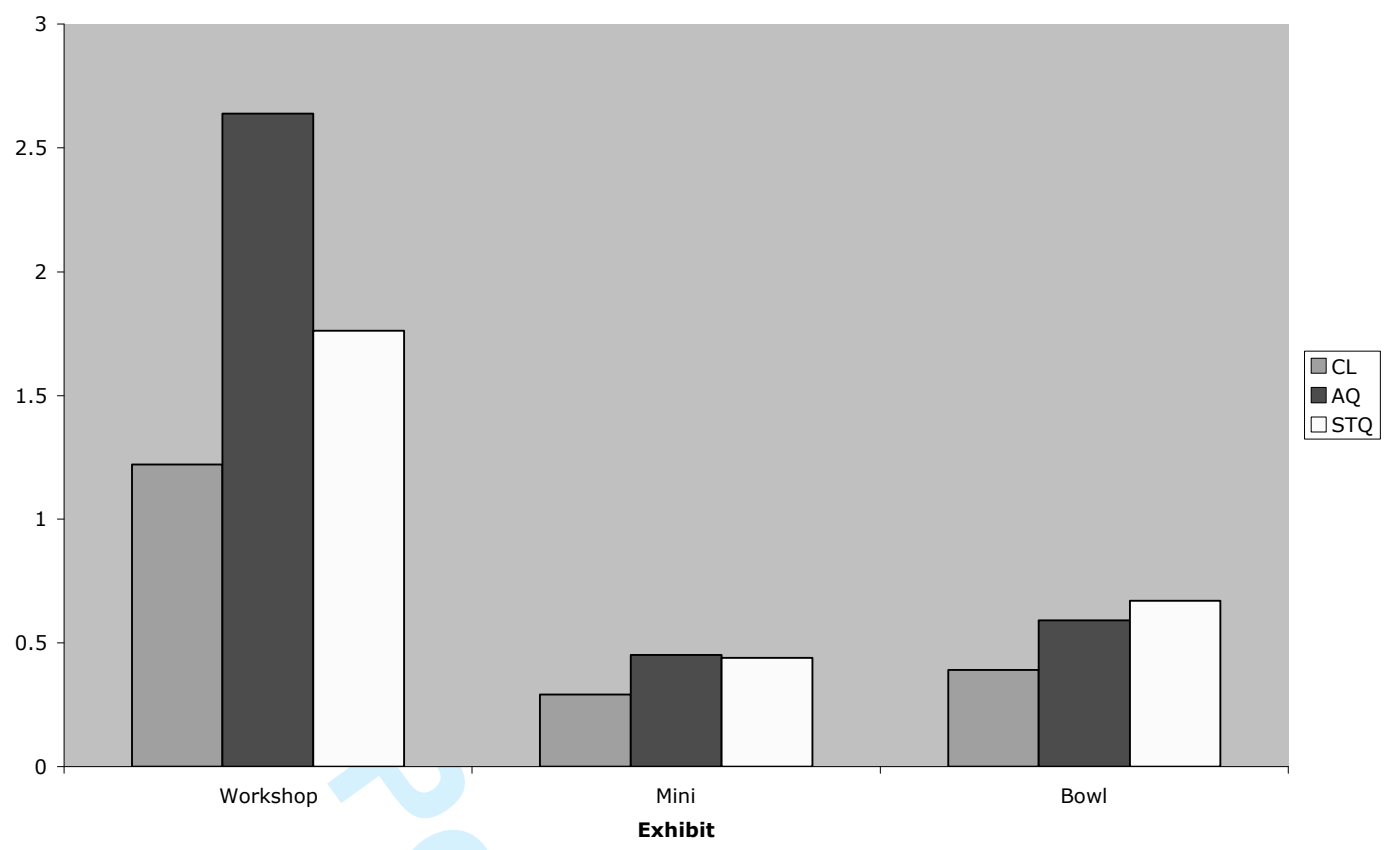

